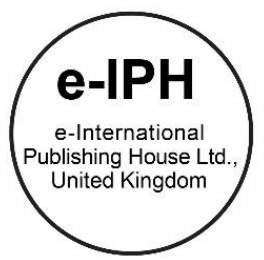

\title{
Patterns of Quality Of Life among Older Urban Dwellers with Mobility Disability in Malaysia
}

\author{
Nik Nairan Abdullah ${ }^{*}$, Mohd Shahril Ahmad Saman ${ }^{1}$, Sabzali Musa Kahn ${ }^{2}$, Waqar Al-Kubaisy ${ }^{1}$ \\ ${ }_{1}^{1}$ Population Health \& Preventive Medicine, Faculty of Medicine, Universiti Teknologi MARA, Sungai Buloh Campus, 47000 Sungai Buloh, Selangor, Malaysia \\ 2 Department of Socio-culture/Malay Art, Academy of Malay Studies, University of Malaya, 50603 Kuala Lumpur
}

\begin{abstract}
Mobility disability affects the quality of life for the older urban population. The objectives of this research paper were to determine the burden of mobility disability and explore influential factors affecting the quality of life of urban community aged 50 and above with mobility disability. Total of 481 participants who were randomly selected from two urban health centres have been interviewed using structured questionnaire in December 2014 . The prevalence of mobility disability was $23.1 \%$. All domains quality of life of older urbanites with mobility disability were significantly affected as compared with those without. These factors need to be emphasized in future planning for elderly.
\end{abstract}

(C) 2016. The Authors. Published for AMER ABRA by e-International Publishing House, Ltd., UK. Peer-review under responsibility of AMER (Association of Malaysian Environment-Behaviour Researchers), ABRA (Association of Behavioural Researchers on Asians) and cE-Bs (Centre for Environment-Behaviour Studies), Faculty of Architecture, Planning \& Surveying, Universiti Teknologi MARA, Malaysia.

Keywords: Mobility disability; urban; elderly; quality of life

\section{Introduction}

An aging population is a challenge that affects developed and developing countries. Monthly, one million people become sixty years old. Furthermore, the projected growth of elderly group will increase in exponentially, and the need for resources to care for older individuals will, therefore, increase proportionately. This growth will also result in an increased incidence of degenerative diseases and disability. This will lead to needs of generating knowledge how to care for this population. Although there is only a minority of this elderly population, however, it requires a large health expenses and multi-professional attention. There are hurdles that need to be overcome as these older age group incur massive healthcare cost. Compressed morbidity is preserving the highest levels of quality of life as possible and reducing the morbidity to a minimal until the point of demise (Luthy et al., 2014).

\footnotetext{
${ }^{*}$ Corresponding author. Tel.: +0-000-000-0000

E-mail address: niknairan@yahoo.com
}

(c) 2016. The Authors. Published for AMER ABRA by e-International Publishing House, Ltd., UK. Peer-review under responsibility of AMER (Association of Malaysian Environment-Behaviour Researchers), ABRA (Association of Behavioural Researchers on Asians) and cE-Bs (Centre for EnvironmentBehaviour Studies), Faculty of Architecture, Planning \& Surveying, Universiti Teknologi MARA, Malaysia.

DOl: https://doi.org/10.21834/e-bpj.v1i2.255 
The quality of life (QoL) is a very broad and complex issue. It has objective and subjective components that cover physical, psychological and social components. The quality of life consists of dimensions and facets that help to define, understand and evaluate the quality of life of an individual. The World Health Organisation established six dimensions in the quality of life domains. The dimensions were physical health, psychological, the level of independence, social relationships, the environment, and spirituality/religion/personal beliefs (Escuder-Mollon et al., 2013).

The quality of life for the elderly is the satisfaction with regards to mental, physical health as well social wellness that involves recognizing the value of themselves (Charoenpoom, 2015). Charoenpoom (2015) stressed that social background was one important factor that affected the well-being of individuals. It involves a multi-level of community activities in association with selfreliance and sustainability relating to strengthening self-esteem, responsibility, decisions making and problems solving.

Apart from preserving a good quality of life, disability is a major problem among elderly. With huge advancement, disability can be prevented or halt the progression. According to Gong et al. (2007), disability is the functional consequence of an impairment and change in a body because of diseases and accidents. This condition will hamper the ability to live and work as an average individual in society and limits major life activities and social activities. Disability is an umbrella term covering impairments, activity limitations, and participation restrictions. Impairment is a problem in body function or structure. Activity limitation is the difficulty encountered by an individual in executing an action. A participation restriction is a problem experienced by an individual in involvement in life situations. The disability can be classified as visual, hearing, physical (mobility), speech and intellectual disability by the body structure; or as a psychological, physical and organic disability by characteristics of the disability; or as congenital and acquired disability. Congenital disabilities accounted for only $9.57 \%$ while acquired disabilities accounted for $74.67 \%$ (Gong et al.,2007).

According to Gill et al. (2006), mobility disability is defined as an inability to walk one 400 metres or to climb a flight of stairs, respectively. The definition of major mobility disability was the failure to complete the 400-meter walk test within 15 minutes. If the 400-meter walk test could not be assessed, self-report and a proxy report were valuable. (Pahor et al.,2006).

The rationale of the study was to elucidate the factors that affect the quality of life to understand better the key issues that should be taken into consideration. This is to enable the elderly to live with better value and to promote quality of well-being (Charoenpoom, 2015). Elderly is the foundation of the family, connections between individuals in different ages in society to the country (Charoenpoom, 2015).

Objectives of this survey were to examine the burden of mobility disability among urban elderly in Malaysia. Furthermore, we aim to explore the quality of life domains and the factors influencing them.

\section{Methods}

In December 2014, we executed a cross-sectional study was conducted in urban health centers in Sungai Buloh and Kepong, Selangor. The inclusion criteria for the survey were Malaysian residents, aged 50 years old and above, able to comprehend, Bahasa Malaysia or English and not bedridden. Total of 481 participants aged 50 and above were randomly selected to participate in this study. A written consent was then obtained from the participants. Participants were ensured of the confidentiality of the information given. Trained research assistants interviewed the respondents using the structured questionnaire.

\subsection{Study instruments}

There were three sections in the questionnaire. Part A - demographic details, self-reported chronic medical disorders and living arrangement; Part B- validated frailty and disability questionnaire (FiND) and quality of life questionnaire (WHOQOLBREF). The quality of life consists of five domains, namely, general quality of life, physical health, psychological, social relationship and environment domains

For data analysis, we utilized Statistical Package for Social Sciences (SPSS) version 20.0. Descriptive analysis was conducted to describe the study population characteristics. Inferential analysis was performed, utilizing t-test and chi-square to determine the significance of hypothesis with $95 \%$ confidence interval $(\mathrm{Cl})$. 


\section{Results and Discussion}

From this study, the prevalence of mobility disability among the respondents was $23.1 \%$. The mean age was $64.6( \pm 8.6)$ years old, refer Table 2. Female respondents $27.9 \%(n=60)$ was more affected compared to the male $19.2 \%(n=51)$. This result was similarly reported by Gong et al.(2007) where they noted that most of the male encountered the disabilities in working age (15-64 years old) or education age (5-19 years old). However, the female usually encountered disability when they entered elderly age group ( 65 years old and over). They also reported the prevalence of mobility and hearing disability for the male was higher than the female. However, the prevalence rate of visual, psychiatric and multiple disabilities were lower than that for the female. According to Luthy et al.(2014), these gender disposition was due to the male behaviour of less reporting problems in mobility. On the other hand, women were more receptive in display and reporting specific problems related to aging. This phenomenon is because they have a longer lifespan as compared to male. Therefore, they have a longer duration of symptoms before death and tend to report more problems and handicaps.

Table 1. Factors influencing psychological, environmental and physical health domains

\begin{tabular}{|c|c|c|c|c|c|}
\hline \multirow[t]{2}{*}{ Influencing Factors } & \multirow{2}{*}{$\begin{array}{l}\text { Frequency }(\mathrm{n}) \\
\mathrm{N}=481\end{array}$} & \multirow[t]{2}{*}{$\%$} & \multicolumn{2}{|c|}{ Mobility disability status } & \multirow[t]{2}{*}{$p$-value } \\
\hline & & & Yes & No & \\
\hline Gender & & & & & 0.02 \\
\hline Male & 266 & 55.3 & $51(19.2)$ & $215(80.8)$ & \\
\hline Female & 215 & 44.7 & $60(27.9)$ & $155(72.1)$ & \\
\hline Marital status & & & & & 0.12 \\
\hline Married-stayed together & 410 & 85.2 & 89(21.7) & $321(78.3)$ & \\
\hline Married -separated & 18 & 3.7 & $3(16.7)$ & $15(83.3)$ & \\
\hline Widow/widower & 44 & 9.1 & $16(36.4)$ & $28(63.6)$ & \\
\hline Never married & 9 & 1.9 & $3(33.3)$ & $6(66.7)$ & \\
\hline Living arrangement & & & & & 0.015 \\
\hline Alone & 13 & 2.7 & $6(46.2)$ & $7(53.8)$ & \\
\hline With spouse & 243 & 50.5 & $62(25.5)$ & $181(74.5)$ & \\
\hline With family member & 225 & 46.8 & $43(19.1)$ & $182(80.9)$ & \\
\hline Regular exercise & & & & & $<0.001$ \\
\hline \multicolumn{6}{|c|}{ (2 sessions of 30 minutes per week) } \\
\hline Yes & 236 & 49.1 & $35(14.8)$ & $201(77.1)$ & \\
\hline No & 245 & 50.9 & $76(31.0)$ & $169(69.0)$ & \\
\hline Hypertension & & & & & 0.009 \\
\hline Yes & 291 & 60.5 & 79(27.1) & $212(72.9)$ & \\
\hline No & 190 & 39.5 & $32(16.8)$ & $158(83.2)$ & \\
\hline Diabetes Mellitus & & & & & 0.001 \\
\hline Yes & 192 & 39.9 & $60(31.3)$ & $132(68.8)$ & \\
\hline No & 289 & 60.1 & $51(17.6)$ & $238(82.4)$ & \\
\hline Limb loss & & & & & $<0.001$ \\
\hline Yes & 8 & 1.6 & $6(75)$ & $2(25)$ & \\
\hline No & 473 & 98.3 & $105(22.3)$ & $368(77.7)$ & \\
\hline
\end{tabular}

Significant $p$-value set at $<0.05$ 
Table 2. Factors influencing general quality of life domain

\begin{tabular}{|c|c|c|c|c|}
\hline Factors & Mean \pm sd & $\begin{array}{l}\text { Mean difference } \\
(95 \% \mathrm{Cl})\end{array}$ & t-value & $p$-value \\
\hline Age & & & 4.93 & $<0.001$ \\
\hline Mobility disabled & $64.6(8.6)$ & 4.4 & & \\
\hline Non-Mobility disabled & $60.2(7.0)$ & $(2.6 ; 6.2)$ & & \\
\hline Household income (RM) & & & 5.96 & $<0.001$ \\
\hline Mobility disabled & 1465(990) & 1083 & & \\
\hline Non-Mobility disabled & 2548(2992) & $(726 ; 1440)$ & & \\
\hline Meeting children within 6 months & & & 2.58 & 0.01 \\
\hline Mobility disabled & $78(81)$ & 23 & & \\
\hline Non-Mobility disabled & $101(84)$ & $(5 ; 40)$ & & \\
\hline Connecting children within 6 months & & & 3.4 & 0.001 \\
\hline Mobility disabled & $91(78)$ & 28 & & \\
\hline Non-Mobility disabled & $120(75)$ & $(12 ; 44)$ & & \\
\hline Meeting grandchildren within 6months & & & 1.04 & 0.3 \\
\hline Mobility disabled & $67(80)$ & 9 & & \\
\hline Non-Mobility disabled & $58(79)$ & $(8 ; 26)$ & & \\
\hline Connecting grandchildren within 6 months & & & 0.13 & 0.9 \\
\hline Mobility disabled & $74(79)$ & 1 & & \\
\hline Non-Mobility disabled & $75(82)$ & $(-16 ; 18)$ & & \\
\hline
\end{tabular}

Our finding is that urban dwellers with mobility disability had significantly lower mean quality of life scores across all domains. The largest mean score difference was general quality health domain. Followed by social relationship domain, environmental domain, psychological domain and lastly, the physical health.

\subsection{General quality of life domain}

The highest mean score difference between mobility disabled and non-mobility disabled older urbanites were in the general quality of life score (mean score difference $=14.9 ; 95 \% \mathrm{Cl} 11.6-18.2, p<0.001$ ). This score exhibited the participant's personal general view of the quality of life. Further analysis of the data showed that the non-mobility disabled older urban dwellers had significant higher household income (RM $2548 \pm 2991)$ as compared those who were mobility disabled (RM 1464 \pm 990 ) $(p<0.001)$, refer Table 2. This result is similar to Charoenpoom (2015)'s study in Bangkok. The author noted that elderly with a stable economic status were able to live with a better quality of life more than those who had less economic stability.

\subsection{Social relationship domain}

Second highest significant mean score difference of quality of life was the social relationship (mean score difference $=9.0$; $95 \% \mathrm{Cl} 5.7-12.3, \mathrm{p}<0.001$ ), where the mobility disabled older urban dwellers had the lower mean score. Further analysis of the data showed intergenerational connectivity played a significant role in the quality of life of the older urban population. There was significance difference of the mean frequency of connecting with own children within six months among those non-disabled as compared those who were disabled (mean frequency difference $=28 ; 95 \% \mathrm{Cl} 12-44, p=0.001$ ). Similarly, meeting with own children within six months among that non-disabled as compared those who were disabled (mean frequency difference= 23; $95 \% \mathrm{Cl} 5-40, p=0.01$ ), refer Table 2 . However, meeting or connecting with grandchildren did not yield any significant difference in 
mean of frequency between non-disabled and disabled. This evidence portrayed that the effect occurred directly between two generations (parents and children) and did not transcend to the third generation.

In 2012, Carmen introduced the ageism concept and the intergenerational practices in Romania. The author elaborated on the social marginalisation of the elderly and the impact of intergenerational practices to overcome the stigma. The elderly were stigmatized when they reach retirement age. It was shown that the greater the number of elderly in a younger person's family and the tighter the relationships between them. Such relationship lowers the level of rejection of elderly by the younger people. Hence, ageism phenomenon is reduced. Besides fostering close relationship, bringing the young and older generations together in through activities and intergenerational projects will improve the understanding between them, increasing the support they provide to one another and ensuring their voices are heard within the communities. Elderly has life experiences that are worth sharing with the younger ones in decision making. Similar to our study, intergenerational connectivity is one of the items in the social relationship that influences the quality of life.

Apart from that, Charoenpoom (2015) noted that elderly with a good social network with the community have positive feelings toward the well-being.

\subsection{Environmental domain}

The third highest significant mean score difference of quality of life was the environmental domain (mean score difference= $8.7 ; 95 \% \mathrm{Cl} 6.2-11.2, \mathrm{p}<0.01$ ), where the mobility disabled older urban dwellers had a lower mean score as compared those who were non-mobility disabled. Living arrangement played a vital role where there was a significantly higher proportion of mobility disability among those who stayed alone as compared those stayed with a family member or spouse $(p=0.015)$, refer Table 1 . This result is supported by Ellen Gee et al.(2006).

Chmelo et al. (2015) reported the importance of exercise in preventing or halting mobility disability in elderly. In term of performing an exercise, a significantly higher proportion who were not performing exercise were mobility disabled $(31 \%)$ as compared those who performed the exercise(14.8\%) $(p<0.001)$, refer Table 1 . With regards the type of regular exercise performed, the majority did regular walking or jogging $(80.5 \%, \mathrm{n}=190)$. Others went for cycling $(6.4 \%, \mathrm{n}=15)$,weightlifting and gymnasium activities $(n=2.9 \%, n=7)$, stretching $(3 \%, n=7))$, playing badminton $(1.7 \%, n=4)$, performed taichi $(2.5 \%, n=6)$, hiking $(1.7 \%, n=4)$ and Yoga $(1.3 \%, n=3)$.

\subsection{Psychological domain}

The fourth highest significant mean score difference of quality of life was the psychological domain (mean score difference= $8.1 ; 95 \% \mathrm{Cl} 5.8-10.4, p<0.01$ ), where the mobility disabled older urban dwellers had a lower mean score. Cagan and Unsal (2014) discussed on depression and loneliness in disabled adults. Also, World Health Organization (WHO) has stated that one of the major causes of depression is the disability. Due to the need to contact and interact with others in life, lack of such will cause mental disorders in individuals (Cagan \& Unsal, 2014).

Among the main risk factors of deteriorated QoL is the social isolation linked to the exclusion and rejection of old age. One of the criteria for assuming the status of being 'old' is the decline of social participation and the feeling of uselessness (Mollon et al. 2013). As people enter the old age period, they may experience age-specific problems and handicaps such as regressions in cognitive and physical health, lead less productive roles and experience changes in social status, declines in interpersonal support and loss of health and this process may bring loneliness (Arslanta et al.,2015).

Moisescu et al.(2014) found that the existence of chronic diseases and physical handicaps, regular use of medication, lack of hobbies increased loneliness. Loneliness inversely affects QoL in old age. He suggested that divorced women or widows are better at coping with loneliness on their own than men. Women occupy their time with activities and hobbies while men are in dire need of help in housework and starts looking for a new life partner. Therefore, this condition will eventually result in improvement of their QoL.

\subsection{Physical health domain}

Lastly, the lowest significant mean score difference of quality of life was the physical health domain (mean score difference= $7.6 ; 95 \% \mathrm{Cl} 5.5-9.6, \mathrm{p}<0.01$ ). The mobility disabled respondents had a lower mean score in contrast to the non-mobility disable. 
Gong et al. (2007) reported that chronic diseases were the high-risk factors for the elderly (65 years old and over) who face disability. Chronic illnesses sufferers such as hypertension and diabetes mellitus have a significantly higher proportion of mobility disability as compared those without hypertension or diabetes mellitus ( $p=0.009$ and $p=0.001$ respectively), refer Table 1 . Similarly, those with limb loss had a significantly higher proportion of mobility disability as compared those without limb loss $(p<0.01)$.

It is such a paradox that physical health domain had the least effect on the quality of life of the urban elderly when the current policy focuses strongly on the health aspects rather than social and environmental domains.

The strength of this study is the validated questionnaire that was able to screen the mobility disabled urban dwellers. In term of limitation of this study, there were few as follows. Firstly, two localities were utilized rather than nationwide population based. Secondly, we do not ascertain whether the respondents with mobility disability experience any mental health symptoms such as depression, stress or anxiety. Also, our result does not apply to elderly who are bedridden.

There is a need for future research to explore in depth the severity of the mobility disability. Furthermore, a qualitative study should be performed as to explore additional items that can be included in the quality of life domains according to the personal perspective cumulatively.

\section{Conclusion and Recommendation}

We found that the quality of life, physical health, psychological, social relationship and environmental factors affected elderly with a mobility disability. It is such a paradox that physical health domain had the least effect on the quality of life of the urban elderly when the current policy focuses strongly on the health aspects rather than social and environmental domains.

Income plays a huge role in sustaining a good quality of life. Government policy should increase the amount of financial aid to the disable elderly. Apart from that, mobility-assisted apparatus prices should be subsided to ensure greater affordability.

Since social relationship has the biggest impact on quality of life among the mobility disable elderly, it is prudent to embark on an intergenerational gap (parents-child) awareness campaign on a large scale. This movement is to ensure the improvement of the family ties in our society that are slowly losing its value the years. Indirectly, it will improve one's quality of life.

Creating a supportive living environment can ensure that the elderly will not be living in isolation. For example, having a caring community in proximity to the elderly housing unit. Combined housing unit catering for both generations at one place is another option.

Health care providers hold a crucial role in strengthening awareness to prevent or halt the chronic diseases using screening and comprehensive treatment. This campaign is one of the measures to preserve the quality of life.

The role of physical education in maintaining functional independence and reducing the risk factors of the disabilities is essential. However, the activities carried out have to be safe and did not pose any risk to injury. The most accessible type of exercise would be walking, jogging, swimming and riding a bicycle. Given the safety and frequent unpredictable environmental hazard such as haze, is high time to make a policy to have indoor facilities at every housing area dedicated for jogging and walking activities. This strategy will enhance the fitness programmes for elderly. In return, this will be able to prevent or halt the progression of mobility disability.

\section{Acknowledgments}

We acknowledge Gombak Health district office for their assistance.

\section{References}

Arslantas, H., Adana, F., Ergin, F. A., \& Kayar, D. (2015). Loneliness in elderly people, associated factors and its correlation with quality of life: A field study from Western Turkey. Iranian Journal of Public Health,44(1), 43-50.

Cagan, O., \& Unsal, A. (2014). Depression and loneliness in disabled adults.Procedia-Social and Behavioral Sciences, 114, 754-760.

Carmen, S. M. (2012). Ageism in Romania and intergenerational practices.Procedia-Social and Behavioral Sciences, 46, 4736-4740. 
Abdullah, N. N., et. al. / 2nd AQoL2015/zmir, Turkey, 09-14 Dec. 2015 / E-BPJ, 1(2) July 2016 (Pp. 55-61)

Charoenpoom, S. (2015).Perceptions of quality well-being among the elderly in the Dusit District, Bangko. Procedia-Social and Behavioral Sciences, 197, 15701574.

Chmelo, E. A., Crotts, C. I., Newman, J. C., Brinkley, T. E., Lyles, M. F., Leng, X., \& Nicklas, B. J. (2015). Heterogeneity of physical function responses to exercise training in older adults. Journal of the American Geriatrics Society, 63(3), 462-469.

Escuder-Mollon, P., Esteller-Curto, R., Issakainen, C., Lubkina, V., \& Lozanova, S. (2014). Pedagogical proposal to increase senior citizens' quality of life. Procedia-Social and Behavioral Sciences, 116, 3152-3159.

Gill, T. M., Allore, H. G., Hardy, S. E., \& Guo, Z. (2006). The dynamic nature of mobility disability in older person. Journal of the American Geriatrics Society,54(2), 248-254.

Gong, C., Bin, C., \& Lei, Z. (2010). Study on the prevention and strategy of disability in China. Procedia-Social and Behavioral Sciences, 2(5), 6906-6913.

Luthy, C., Cedraschi, C., Allaz, A. F., Herrmann, F. R., \& Ludwig, C. (2014). Health status and quality of life: Results from a national survey in a communitydwelling sample of elderly people. Quality of Life Research, 1-10.

Moisescu, P. C. (2014). The social integration of elders through free-time activities.Procedia-Social and Behavioral Sciences, 116, $4159-4163$.

Pahor, M. (2006). Effects of a physical activity intervention on measures of physical performance: Results of the Lifestyle Interventions and Independence for Elders Pilot (LIFE-P) study. The Journals of Gerontology: Series A:Biological Sciences and Medical Sciences. 